Article

\title{
Loss Assessment for Sustainable Industrial Infrastructure: Focusing on Bridge Construction and Financial Losses
}

\author{
Ji-Myong Kim, Taehui Kim and Sungjin Ahn * \\ Department of Architectural Engineering, Mokpo National University, Mokpo 58554, Korea; \\ jimy@mokpo.ac.kr (J.-M.K.); thkim@mokpo.ac.kr (T.K.) \\ * Correspondence: sunahn@mokpo.ac.kr; Tel.: +82-61-450-2456
}

Received: 22 April 2020; Accepted: 28 June 2020; Published: 1 July 2020

check for updates

\begin{abstract}
Bridges are important infrastructures for urban growth and the economic development of a country, because bridges allow a large volume of logistics and transportation by connecting rivers, canyons, islands and lands. As such, massive resources including financial, material and human resources are invested for bridge construction and management. However, although the latest bridge construction is undergoing rapid development of new technologies and designs, the management and prevention of risks still tend to rely on qualitative practices, which, as a result, calls for more quantified and systematic measurement and, thus, more sustainable management of potential risks. As part of efforts in managing risks to achieve quantitative risk management, this study aimed to predict losses of financial resources by identifying statistically significant risk factors based on the past record of insurance claim payouts (compensation for a loss that occurred as a result of a material damage in bridge construction projects) from a major insurance company in Korea, and conducted a multiple regression analysis to identify the loss indicators and to develop a loss estimation model. The statistical analysis confirmed that superstructure types, superstructure construction methods, and construction duration are the three significant risk factors that affects financial losses of bridge construction projects among the seven variables adopted as independent variables, which included the superstructure type, maximum span length, superstructure construction method, foundation type, floods, typhoons, and construction duration. Such findings, and the consequentially developed risk prediction model of this study, will contribute to sustainable construction management through cost reduction by predicting and preventing the future financial loss factors of bridge construction.
\end{abstract}

Keywords: quantitative loss assessment; bridge construction; sustainable risk management; insurance

\section{Introduction}

As the sizes of recent construction projects grow and the methods of construction become highly diversified, a variety of uncertainties are on an increasing trend, accompanied by many new risk factors. Thus, the need for a more systematic and reliable risk management is continuously being emphasized in the entire process of construction projects. However, such construction risk management techniques seem rather insufficient in the field, as they have not yet been established in actual practice in trend [1]. For example, the risk assessment used in most construction projects tends to rely on subjective and qualitative information based on the experiences and opinions of individual contractors and construction managers [2,3], rather than on technical analysis and verification. Especially in bridge construction, various accidents occur, which can result in significant human injuries and material damages, because bridge construction is exposed to various types of risks that tend to be more extreme and severe than those of other types of construction sites, due to environmental conditions such as 
streams, rivers, and canyons, as well as work conditions such as high place work and heavy equipment operations. In addition, many recently built bridges tend to be long-spanned, complicated structures, as a result of a high degree of the development of new technologies and design strategies, which can also cause extensive losses if accidents happen with the increased risk factors associated with the complexity of the work processes. Yet, as briefly mentioned above, decisions relating to risk assessment and management are often made based on insufficient and/or subjective information [2-4]. Therefore, more research-based and empirical risk factors are required to be verified and used in analyzing and predicting to prepare for the possible damages and accidents. As such, risk management measures should identify various risk factors throughout the whole process of the construction in advance, in order to estimate and analyze the extent of the potential damages and losses according to their causes, based on as minimal information as reasonably possible [5-8]. With this background, the purpose of this study is to provide the risk prediction model that can contribute to minimizing risks in more systematical and evidence-based way. In other words, this study aims to first identify the statistically significant risk factors in bridge construction projects inherent in the process from onset to completion and to present a risk prediction model, while reflecting the actual record of damages which occurred in bridge construction projects, both of which ultimately aim to achieve sustainable risk management.

\section{Review of Literature}

\subsection{Need for Quantifying the Risks and Loss of Construction Projects}

The objective of the risk analysis is to establish effective and sustainable strategies to proactively prevent and manage possible risks, ultimately to better allocate and commit financial resources in construction projects. The concept of risk is variously addressed in a wide range of fields and areas in an effort to identify, measure and control the risks. Table 1 below lists the various Interpretations of risk from different studies.

Table 1. Interpretations of risk.

\begin{tabular}{cc}
\hline Author & Interpretations of Risk \\
\hline Morgan and Henrion (1990) [9] & Degree of exposure to damage or loss \\
\hline UN DHA (1992) [10] & Loss expected due to a disaster in a particular period and region \\
\hline Stenchion (1997) [11] & Probability of the occurrence of an undesirable event \\
\hline Crichton (1999) [12] & $\begin{array}{c}\text { Probability of losses consisted of three elements: disaster, } \\
\text { exposure, and vulnerability }\end{array}$ \\
\hline Jones and Boer (2003) [13] & $\begin{array}{c}\text { A combination of probability of a potential event causing } \\
\text { damage and the consequence }\end{array}$ \\
\hline
\end{tabular}

Analyzing risk provides a means to cope with many possible risks, as it helps identifying appropriate and effective strategies to confront, avoid and reduce the risks. Nonetheless, risk analysis has not been in the center of attention for long in the literature, compared to such topics as cost and schedule management in construction projects. Furthermore, it has traditionally been qualitative methodologies used for risk analysis in construction projects, rather than quantitative methodologies, even though quantitative methodologies enable not only more factual and accurate risk analyses, but also provide a more reliable and generalizable measurement for examining and analyzing the risks. With quantitative risk analysis methodologies, it is possible to model and analyze nearly all construction projects by quantifying the factors of risks, their actual occurrence and impact. For this reason, recent studies in risk analysis have started to adapt qualitative methodologies, although much of the previous research has been conducted qualitatively.

The construction industry inclines to complexity and specificity of the projects and is considered a high-risk area, as it involves a large number of project participants, long period of project time and the large cost scale. Such technical and strategic complexities, in turn, create a great deal of risks based on 
uncertainty [14]. Yet, although many studies have been conducted on risk management, the topic of risk assessment remains a controversial issue [15], in terms of its data and methodologies of analysis. For example, conventional risk management data and methodologies remained in the qualitative realm, which can be inadequate in precisely measuring, quantifying and enumerating the risks. On the contrary, quantitative data and methodologies can provide more sophisticated, accurate and reliable risk assessments and prediction, because it adopts more mathematical and statistical way to perceive and cope with the risks.

Although the construction industry is considered a high-risk industry compared to other industries, e.g., insurance and finance, the attitude toward and application of risk assessment are reported in many studies to be rather inadequate [16]. For example, Baker et al. [17] inquired construction companies to examine the effective risk assessment techniques the companies used. They found that individual owners' or experts' personal experiences and engineering judgment were the most frequently used assessment strategies. Wood and Ellis [2] also reported that personal experiences and underlying judgement are the main risk assessment factors and that risk management is generally conducted in rather simple and primitive ways, such as checklists and surveys. Similarly, noting that qualitative methods were more frequently used than quantitative methods in studies on construction risk assessment, Dikmen et al. [3] addressed the need for a quantified approach to organize subjective assessment factors such as individual experts' experiences, knowledge and intuitive decisions regarding the identification of possible risk factors.

As can be seen, the literature regarding risk assessment has pointed out that the field has lacked in quantitative approaches in assessing and analysis risks, although quantitative measures can provide factual and numerical values and, in turn, a more systematic understanding for decision making [18]. Upon the findings that the sensitivity analysis was frequently used for risk analysis in construction projects, Warszawski and Sacks [19] concluded that, because construction projects tended to be one-off enterprises and the input information required is not sufficient, more advance and refined analysis methods approaches were not generally adopted. Many studies [20-23] have frequently adopted risk cost as impact measurement scale for risk analysis. Although many researchers have done risk analysis on different project goals, they have used little of the actual risk cost due to limits of data acquisition. For this reason, using risk cost for assessment scale seem to make much improvement in increasing the validity and accuracy of risk analysis. Keshk et al. [24] examined various types of risks to consider in quantitative and qualitative analysis for construction project management and indicated that, although it is impossible to locate the one strategy to deal with all risks, quantification of types and sizes of risks can greatly affect the strategies for responding to the risks.

As discussed, the literature has focused on various types of approaches to examine the factors for risk management. Many studies pointed out that it is almost impossible to exclude qualitative data such as opinions of experts and their personal experiences and called for the ways to quantitatively interpret such qualitative data. On that account, in risk assessment, quantitative assessment is necessary for advancing and improving the validity of risk factor analysis, while being accompanied by quantifying the available and reasonable data.

\subsection{Risk Management for Sustainable Construction}

Traditional or typical enterprise risk management has tended to overlook the unexpected risks and other risks caused from unpredictable events; in turn, such risks have failed to be encompassed in assessing Enterprise Risk Management (ERM) strategies. For this reason, many business and companies are now realizing that considering emerging or unforeseeable risks is essential for their survival in the industry for the long run [25]. One way for more effective, long-term risk management strategies is to adopt the concept of sustainability. The concept of sustainable construction is to provide the stakeholders with long-term economic feasibility, high quality and efficiency, while reducing negative environmental impacts and enhancing economic sustainability [26]. In addition, sustainable risk management requires appropriate management of information and knowledge of risks and 
uncertainties [27]. In particular, sustainable risk management in the field of construction needs to meet the environmental challenges, to respond to social needs and to deliver economic improvement. For this reason, sustainable risk management in construction focuses on the development of infrastructure to achieve development that meets the economic, social and environmental needs of future generations, as infrastructure is not just a means of generating corporate profits, but rather a type of public good that plays an important role in influencing economic development and its impact on social needs [28]. These infrastructure development projects are mostly large, complex and capital intensive, therefore innovative financial strategies are needed [29]. For instance, the Hong Kong government adopted three weighted criteria (65\% finance, $20 \%$ engineering, and $15 \%$ planning of operation and transport) to evaluate contractors for the infrastructure project. The weights assigned to the financial criteria in this assessment reflect the importance of sound financial planning for the success of infrastructure projects [30].

Analysis and evaluation are essential elements of risk management, and the analysis consists of the extent of the results and the best evaluation means that can be used to characterize the probability [31]. One of the many aspects of sustainable risk management that is distinct from traditional or typical risk management is that, as mentioned earlier, it encompasses the management of risk factors and potential uncertainties that are difficult to predict. This study addresses and contributes to the concept of sustainable risk management in that, based on existing loss records, potential risk factors and environmental disaster factors have been identified and were used to develop the loss estimation model in bridge construction, one of infrastructure development. Specifically, it provides essential and key data for plan and management that minimizes losses in advance to prepare for emerging and unforeseeable risks and to optimize the overall life of bridges.

\subsection{Risks in Bridge Construction}

Various studies on risk factors specifically in bridge construction have also been conducted in many regions and countries. Among them, the following Table 2 shows the key elements and analysis methods for the bridge construction risk analysis in a few major relevant studies.

Table 2. Previous research on bridge construction projects.

\begin{tabular}{|c|c|c|c|}
\hline Author & $\begin{array}{l}\text { Key elements in Bridge } \\
\text { Construction Risk Analysis }\end{array}$ & Risk Data Collection & Analysis Method \\
\hline Wang and Elhag (2007) [32] & $\begin{array}{l}\text { (1) Safety, (2) Functionality, (3) } \\
\text { Substantiality, (4) Environment }\end{array}$ & $\begin{array}{l}\text { Team of bridge } \\
\text { experts' rating }\end{array}$ & $\begin{array}{c}\text { Fuzzy Group Decision } \\
\text { Making (FGDM) approach }\end{array}$ \\
\hline Decò and. Frangopol (2011) [33] & $\begin{array}{l}\text { (1) Traffic loads, (2) Environmental } \\
\text { attacks, (3) Scour, (4) Earthquakes }\end{array}$ & $\begin{array}{l}\text { Databases: National Bridge } \\
\text { Inventory (NBI)), U.S. } \\
\text { Geological Survey (USGS), } \\
\text { water data (USGS2010) }\end{array}$ & $\begin{array}{l}\text { Probabilistic evaluation of } \\
\text { time-dependent }\end{array}$ \\
\hline Hashemi et al. (2011) [34] & $\begin{array}{l}\text { (1) Delayed payment on contract } \\
\text { and extras, (2) Shortage of labor, } \\
\text { material, and equipment (3) } \\
\text { Construction permitting issues (4) } \\
\text { Poor relationship among parties }\end{array}$ & $\begin{array}{l}\text { Questions and interviews } \\
\text { with bridge experts }\end{array}$ & Bootstrap Technique \\
\hline Li et al. (2011) [35] & $\begin{array}{l}\text { (1) Economic risk, (2) Contract and } \\
\text { law risk, (3) Building technology } \\
\text { risk, (4) Design risk, (5) } \\
\text { Environment risk, (6) Staff risk, (7) } \\
\text { Material and equipment risk }\end{array}$ & $\begin{array}{l}\text { Survey questionnaires from } \\
\text { project stakeholders }\end{array}$ & Factor Analysis \\
\hline Choudhry et al. (2014) [36] & $\begin{array}{l}\text { (1) Financial risks, (2) Contractual } \\
\text { risks, (3) Design risks, (4) Health } \\
\text { and safety risks, (5) Management } \\
\text { risks, (6) Construction risks, (7) } \\
\text { External risks }\end{array}$ & $\begin{array}{l}\text { Interview and interviews } \\
\text { with expert panels }\end{array}$ & Monte Carlo simulation \\
\hline
\end{tabular}

As can be seen, various studies used different analysis methods to derive the factors of risk management in bridge construction projects. Most of them aimed to interpret qualitative data in quantitative ways. However, it would not be unreasonable to exclude the limitations of subjective and 
intuitive aspects of the qualitative data itself. Therefore, it is necessary to statistically verify the risk factors and develop a prediction model using a quantified and specific database, such as risk costs and loss amount.

\section{Risk Factors for Bridge Construction}

\subsection{Construction Insurance}

Construction All Risks (CAR) insurance is insurance protection under which the contractor, builder, and others involved in construction projects are collectively covered for damages to the construction object, materials used, and equipment, injuries and deaths, or damages to the property of a third party incurred by unexpected accidents during the construction projects. The coverage of the CAR insurance policy is classified into a bridge, port, railway, road, building, tunnel, plant and water resources-related construction, and covers the risks during the entire construction period from the start to the transfer to the contractor after completion. As mentioned, this study adopted the record of insurance claim payout. However, the scope of this study is limited to focus on the damages to the materials incurred in the phase of construction only, excluding the maintenance phase.

Bridge Material loss means any damages for construction materials within the construction sites occurred during construction and civil engineering works, such as temporary construction work, main construction, and damage to the construction materials. Various accidents caused material loss are as follows

- Damage caused by fire, lightning, explosion, and fire extinguishing operations;

- Damage caused by floods, floods, rainfall, snowfall, tidal waves, etc.;

- Damage caused by storms, earthquakes, ground subsidence, soil, rock collapse, etc.;

- Theft;

- Various electrical accidents such as short circuits, short circuits, etc.;

- Damage caused by a mechanical defect, worker's carelessness, or construction defect.

For risk analysis, this study collected data from construction insurance coverage of the bridge construction project from 1999 to 2017, among which 367 material damage insurance claim payout data were selected and used. Among many possible elements for measuring risks in bridge construction found in the data, this study perceived and articulated three types of information including accident information (accident dates, accident location address and details), technical information (superstructure types, foundation types, superstructure construction methods, and the maximum span length) and project scale (project duration).

\subsection{Risk Factors}

\subsubsection{Superstructure}

When deciding the superstructure type in a bridge construction project, a comprehensive consideration of economic constructability and safety, along with topographical and environmental conditions, should be given at the planning phase. Previous studies have suggested that the characteristics of the superstructure type of a bridge are distinguished by the conditions, and estimated construction cost, and that the optimal superstructure can thus be selected according to the conditions $[37,38]$. The Korean Public Procurement Service classified the grade of the bridge into Class A (suspension bridge, cable stayed bridge, bridge $200 \mathrm{~m}$ or more in span), Grade B (bridge connecting islands and land, bridge connecting island and island, arch bridge, truss bridge, bridge $100 \mathrm{~m}$ or more but less than $200 \mathrm{~m}$ in span), Grade C (bridge $50 \mathrm{~m}$ or more in span, general bridge over $1000 \mathrm{~m}$ ), and Class D (general bridge over $500 \mathrm{~m}$ ) according to the difficulty of construction in the contractor Pre-Qualification (PQ) criteria for bridge construction [39]. This distinction by size and difficulty of constructing can be used in consideration for the main measure of risk analysis for bridge 
construction. In this study as well, the superstructure types were classified in order of nominal scale of arch bridges, pre-stressed concrete I-type (PSCI) and cable-stayed bridges by the distribution of the average compensation.

\subsubsection{Maximum Span Length}

As with the superstructure types, the length of the bridge is an important criterion for the difficulty of rating of the PQ review for constrictors, and for long-spanned bridges, the risk can be increased due to the relative increase in construction period, cost and wind speed [40-42]. In this study, nominal scales were classified on the basis of below 50,100 , and $500 \mathrm{~m}$.

\subsubsection{Foundation Types}

In terms of deciding bridge foundations, the quantity and rate of river flow play a significant role. If the quantity and rate of river flow increase rapidly in a short period of time due to torrential rain or flooding, the sudden scour of the bridge foundation can happen and it may cause unexpected bridge collapse accidents. As such, scour can be an important point in maintaining the life or stability of a bridge [43]. The foundation of a bridge is a crucial structural element in bridge construction and holds significant risk factors and uncertainties, which necessitate the hazard management [44]. Therefore, the information on the bridge foundation types from the collected data was also utilized as a risk factor in the analysis and, based on the comprehensive consideration of the construction difficulty and loss compensation, the nominal scale classification for the analysis was established as follows: precast concrete pile, cast in place, open caisson.

\subsubsection{Superstructure Construction Method}

Previous studies have evaluated the optimal structural safety design method by the bridge construction method, focusing on the influence of the load according to the construction method and the need for economic design methods [45-48]. In other words, the risk analysis based on the characteristics of the construction method and its classification are necessary. Kim and Cho classified the typical construction methods of the bridge superstructure as ILM (Incremental Launching Method), FCM (Free Cantilever Method), FSM (Full Staging Method), and MSS (Movable Scaffolding System), applying them to the rough construction cost estimation, which allowed identifying differences in characteristics of superstructure construction method [49]. In this study, the criteria for classification of superstructure construction methods was established on the basis of the nominal scale of ILM, FCM, FSM, and MSS, based on the average amount of compensation sorted by the superstructure construction method.

\subsubsection{Total Duration}

The duration of the construction projects was often used as a measure of risk analysis in previous studies [50,51], and it could also be a significant measure of loss. For construction projects, it was confirmed in studies that the longer the construction period, the less the amount of the loss. This study as well adopted the factor of construction duration, i.e., number of months spent for the projects, in the analysis.

\subsubsection{Typhoon and Flood}

The risks of natural disasters are calculated by the indicators of floods and typhoons, using the reinsurer's Natural Disaster Assessment Network map. It is designed to accurately evaluate the characteristics of a particular place, with regard to natural disasters such as floods, storms and earthquakes. This study selected and used the risks as to the intensity of typhoons and occurrence of floods, because floods and typhoons are the typical natural disasters in Korea that affect bridge construction. NATHAN (Natural Disaster Assessment Network) provided the differentiation in the 
regional zones which then represented the intensity of typhoons and occurrence of floods using location information (address) from insurance claim payout data. In other words, the flood occurrence and typhoon intensity were chosen as independent variables. Figure 1 shows the nominal scale by typhoon intensity and flood occurrence.

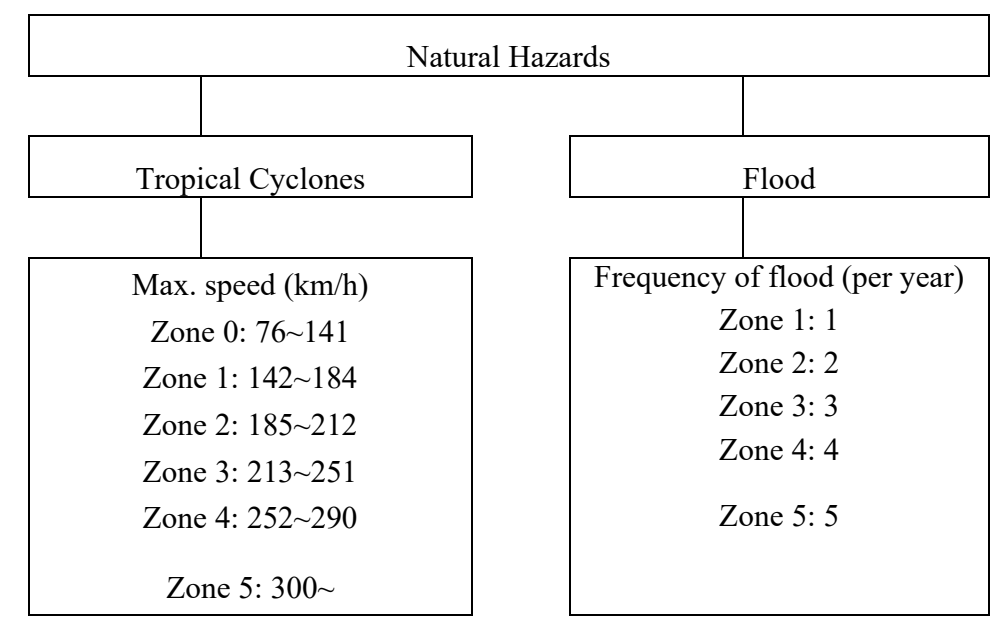

Figure 1. Natural hazards factors.

The Figure 2 indicates the average compensation distribution by each variable, which show the criteria for selecting the ordinal scale.

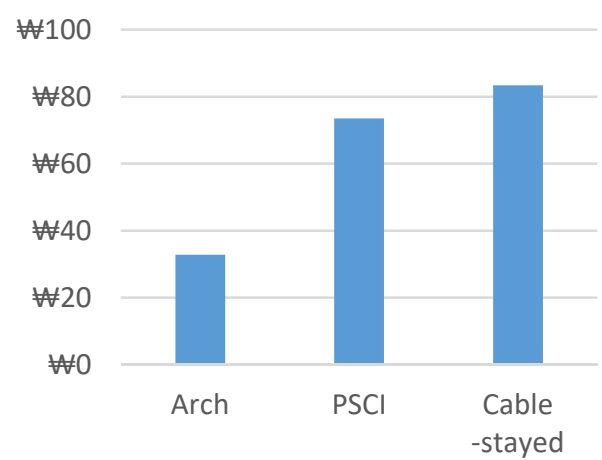

(a) Superstructure

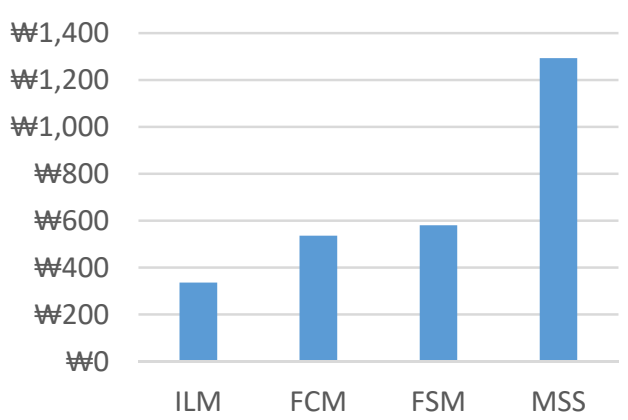

(c) Construction Method

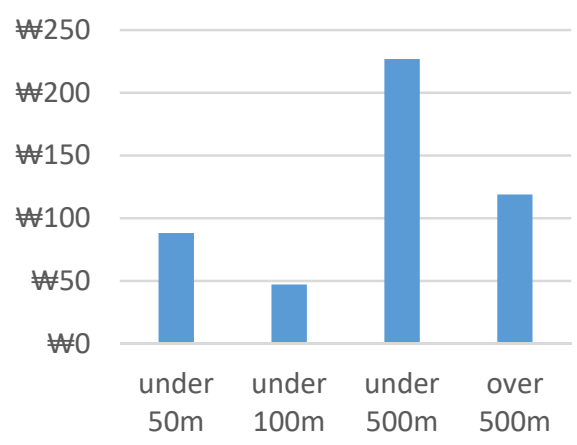

(b) Max. Span Length

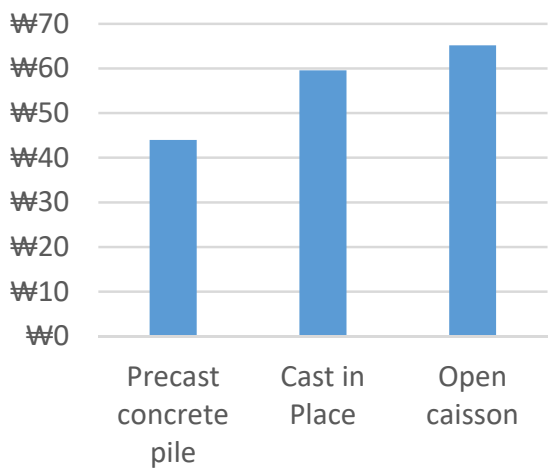

(d) Foundation

Figure 2. Cont. 


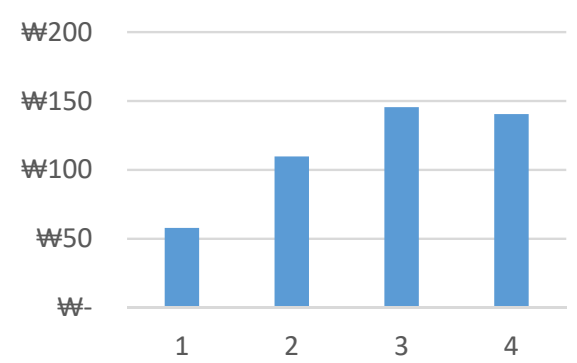

(e) Flood

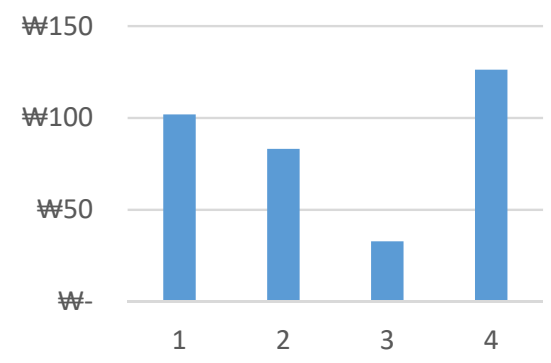

(f) Typhoon

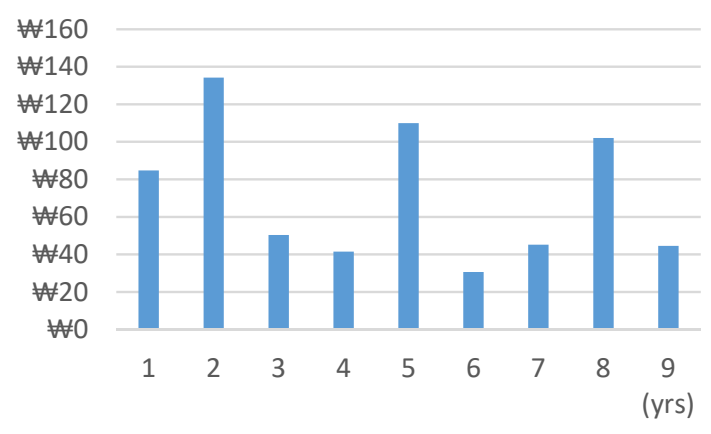

(g) Total Duration

Figure 2. The average compensation distribution.

\section{Data Analysis and Result}

\subsection{Data Collection and Method}

The risk management measures in construction are classified into five categories, such as risk retention, avoidance, reduction, transfer and sharing [52]. In the general construction industry, risk management focuses on reducing risk factors along with the transferring risks through insurance [53]. In this study, the risk factors in bridge construction are analyzed, based on the data regarding 367 cases of material damages in actual projects and ensuing insurance claim payouts (compensation made for losses that occurred as a result of material damages in bridge construction projects), collected from a major insurance company in Korea, in order to develop a damage prediction model that estimate the possible financial losses in bridge construction. More specifically, in this study, the statistically significant risk factors were drawn through the claim payout data by a regression analysis; in the process, the derived risk factors and the loss ratio were selected as independent and dependent variables, respectively, to identify the correlation. Figure 3 outlines the flow of analysis.

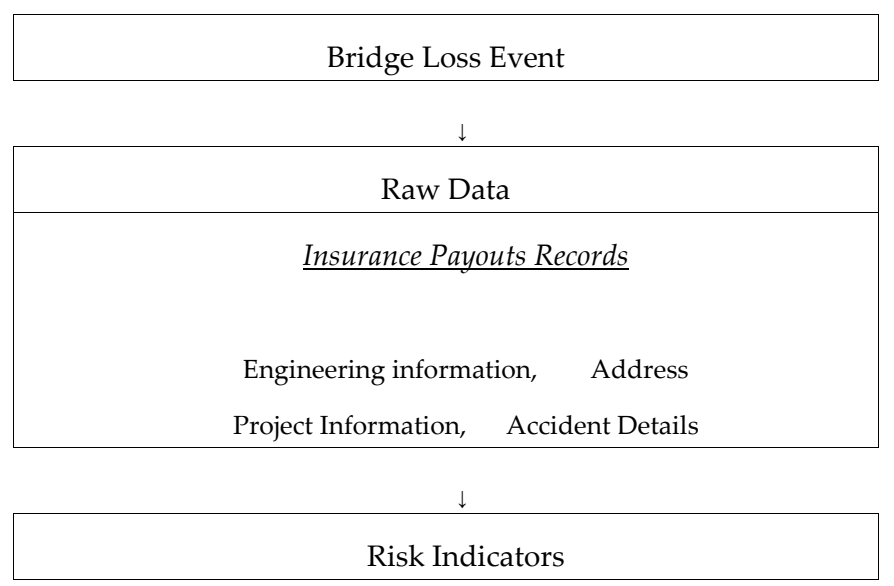

Figure 3. Cont. 


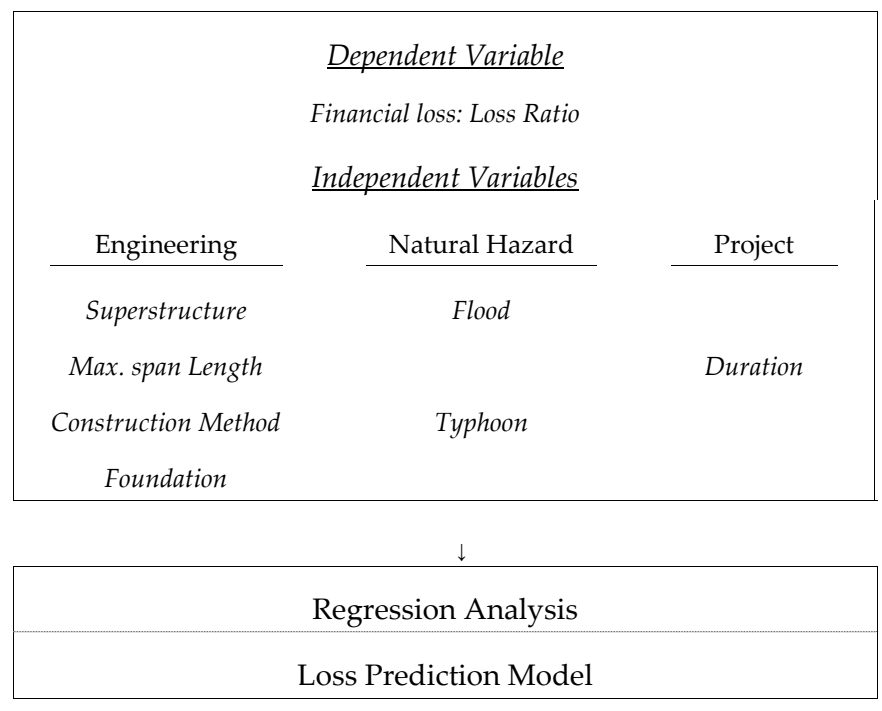

Figure 3. Analysis procedure.

The risk prediction model that estimates the possible financial loss in bride construction, which was developed in this study is intended to utilize the basic or minimal information in the context of a lack of existing accumulated data regarding damages and losses, in order to provide a plan for the development of quantitative risk models and a basis for sustainable risk management.

\subsection{Regression Analysis}

\subsubsection{Dependent Variable}

In order to objectively and quantitatively measure the loss, the dependent variable is expressed as "loss ratio," which is the amount of the insurance payout divided by the Total Sum Insured (TSI), corresponding to each accident case of insurance claim. This concept and term of "loss ratio" was developed in this study to reflect the possible differences and particularities depending on the size and scale of each bridge construction project. In other words, it seems reasonable to consider the fact that, even when the loss amount is relatively low in a project, if the size of the project is rather small the extent of the loss can be more detrimental and severe; Although seemingly paradoxical, it is also possible that, even when the loss amount is relatively high, if the size of the project is rather large, the extent of the loss can be considered somewhat benign and slight. The loss ratio is expressed in the following Equation (1):

$$
\text { Loss Ratio }=\text { IP/TSI }
$$

Here, IP: Insurance Payout and TSI: Total Sum Insured.

In each case, the material's losses were relatively very small compared to the total sum insured. The distribution of loss ratio is a positive-skew distribution, which means it has a long right tail when expressed by Equation (1). For this reason, each dependent variable, loss ratio, was transferred by natural $\log$ in order to fit the normal distribution. The value of the transferred loss ratio, dependent variable, used in the regression analysis is shown in Equation (2):

$$
\text { Transformed Loss Ratio }=\text { Ln }(\mathrm{LR})
$$

In the model presented by this study, the predicated value of $y(\hat{y})$ is the logarithm of the loss ratio. The value of the predicted loss ratio represents the value of the loss ratio within the range of $0-1$. No loss whatsoever is represented by ' 0 ' and ' 1 ' represents an entire loss. The $L$ (Predicted Ratio) value derived as a result of a valid regression analysis is expressed as a decimal number by Equation (4), 
which allows the relative comparison of quantified scale to determine the level of the loss. This ratio in fact was also used in several other studies as a measure of quantitative loss and risk [50,53,54].

$$
\operatorname{Ln}(\text { Predicted Ratio })=\beta_{0}+\beta_{1} \cdot X_{1}+\beta_{2} \cdot X_{2}+\beta_{3} \cdot X_{3}+\ldots
$$

where, $\beta_{0}=$ Y-intercept; $\beta_{1}, \beta_{2}, \beta_{3}=$ Coefficient; $X_{1}, X_{2}, X_{3}=$ Independent variables.

$$
\text { Predicted Ratio }=\mathrm{e}^{\beta 0+\beta 1 \cdot \times 1+\beta 2 \cdot \mathrm{X}_{2}+\beta 3 \cdot \mathrm{X}_{3}+\ldots}
$$

\subsubsection{Independent Variables}

In order to set up the group of independent variables, the abovementioned data and information (Section 3.2) were utilized and the following risk indicator categories were developed: (1) bridge engineering factors, (2) natural disaster factors, and (3) project information of bridge construction. The first category, which is bridge engineering factors, consists of the superstructure types, foundation types, superstructure construction methods, and maximum span length. The second category, natural disaster factors, includes the intensity of flooding and typhoons. The third group, project information, includes the construction duration and the total construction cost. Table 3 organizes the categories and included variables.

\begin{tabular}{|c|c|c|c|}
\hline Category & Variables & Unit & Description \\
\hline \multirow{4}{*}{ Engineering factor } & Superstructure & Number (Ordinal Scale) & $\begin{array}{l}\text { 1: Arch bridge } \\
\text { 2: PSCI beam bridge } \\
\text { 3: Cable-stayed bridge }\end{array}$ \\
\hline & Max span & Meter & Maximum span length \\
\hline & Construction Method & Number (Ordinal Scale) & $\begin{array}{l}\text { 1: ILM (Incremental Launching Method) } \\
\text { 2: FCM (Free Cantilever Method) } \\
\text { 3: FSM (Full Staging Method) } \\
\text { 4: MSS (Movable Scaffolding System) }\end{array}$ \\
\hline & Foundation & Number (Ordinal Scale) & $\begin{array}{l}\text { 1: Precast concrete pile } \\
\text { 2: Cast in place } \\
\text { 3: Open caisson }\end{array}$ \\
\hline Natural hazard factor & $\begin{array}{l}\text { Flood } \\
\text { Typhoon }\end{array}$ & $\begin{array}{l}\text { Number (Zone) } \\
\text { Number (Zone) }\end{array}$ & $\begin{array}{c}\text { Frequency of flood in local area } \\
\text { Max. speed of Typhoon in local area }\end{array}$ \\
\hline Project factor & Duration & Month & Total duration of the project \\
\hline
\end{tabular}

Table 3. Categories of risk indicator.

Here, variables such as superstructure types, foundation types, and construction methods were not used to evaluate the levels of safety, but to identify the change in the loss rate and thus influence on the financial losses. This was done by sorting the loss levels of each type into nominal scales, based on the actual loss data of the particular type. This process was to provide reasonable evidence for the analysis by determining statistical significance.

\subsubsection{Validation of the Model}

To provide statistical evidence of the significant risk factors in bridge construction, the normality of the data has been tested using Shapiro-Wilk tests. When each value was put into the equation, the Loss Ratio is inclined toward zero with a high skewness value, because the majority of the project cost tend to be extremely large, compared to the loss. Yet, the distribution of the Loss Ratio satisfied the normality through natural $\log$ transformation. Shapiro-Wilk normality tests also provides the clear evidence of the normal distribution (Table 4). 
Table 4. Normality test of dependent value.

\begin{tabular}{cccc}
\hline \multicolumn{4}{c}{ Shapiro-Wilk Test } \\
\hline & Statistic & df & sig. \\
\hline LR & 0.377 & 367 & 0.000 \\
Ln(LR) & 0.948 & 367 & 0.087 \\
\hline
\end{tabular}

Additionally, the normal P-P plot of regression standardized residual and residual scatterplots are used to test whether the basic assumptions of regression analysis, normality of standard residuals and homoskedasticity are satisfied. The normal probability plot in Figure 4a shows the scatters of the residuals' approximately linear pattern without any extreme outliers. This means that the error terms are indeed normally distributed.

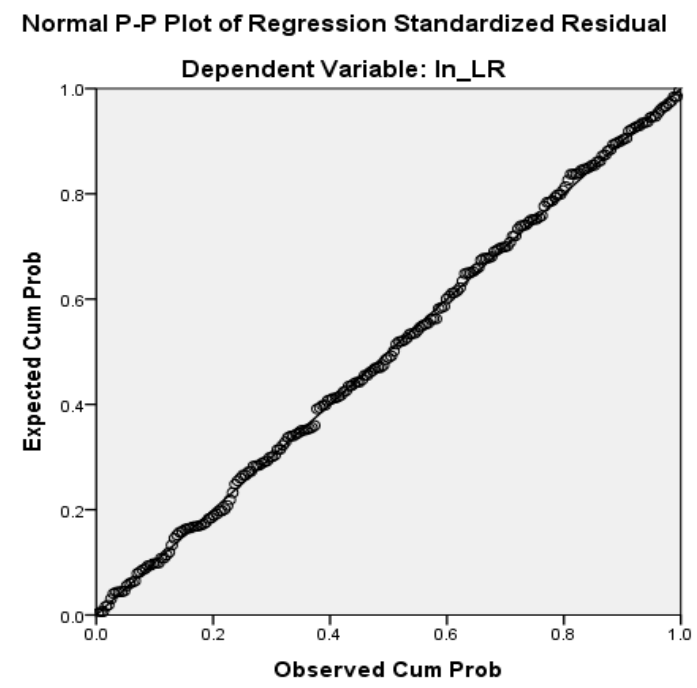

(a) Normal P-P plot

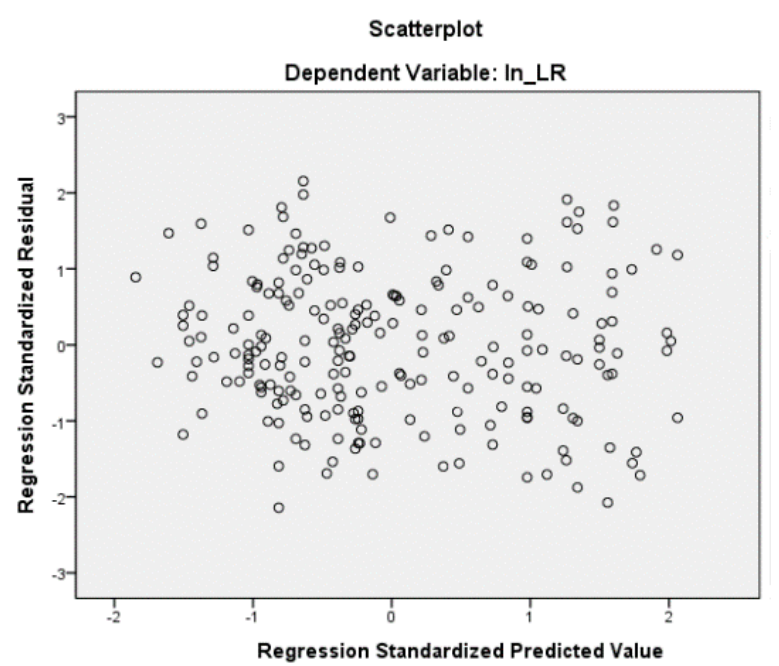

(b) Standardized residual scatter plot

Figure 4. Validation of regression model.

By plotting the standardized residuals against the standardized predicted values as shown in Figure $4 \mathrm{~b}$, the assumption of homoscedasticity for regression analysis was not violated. In general, the scatter plot should be distributed between -2 and +2 at the regression-standardized-predicted value (the horizontal axis), and the regression-standardized residuals (the vertical axis) are also considered to be good for homogeneity of variance when they are distributed between -2 and +2 .

Table 5 displays the results of the regression model. As mentioned earlier, for the independent variables, seven variables in total were adapted including superstructure types, maximum span length, foundation types, superstructure construction methods, typhoon intensity, flood intensity, and total construction duration. The analysis found that, among these seven independent variables, three of them including superstructure types, superstructure construction methods and the total construction duration are the significant risk indicators that affected the loss ratio, in other words, the amount of the loss in bridge construction. In addition, the maximum span length, foundation types, typhoon intensity, and flood occurrence were not statistically significant, which indicates no correlation with the loss ratio. In the regression analysis of the loss ratio of the bridge construction, as can be seen in Table 5, the revised $R^{2}$ value is 0.315 , which indicates the $31.5 \%$ of explanation power of the regression model. The $R^{2}$ value can be increased when additional significant variables other than those presented are reflected. Furthermore, the range of VIF values is between 1.033 and 1.050, which means that there is no multicollinearity between the variables. A standardized beta coefficient compares the strength of the effect of each individual independent variable to the dependent variable. In other words, a standardized regression coefficient indicates the importance of the regression coefficient; and the higher the value 
of the beta coefficient of the variable, the greater the effect on the dependent variable. When the absolute value of the beta coefficient of each indicator is expressed in descending order, it would be organized as follows: (1) bridge superstructure type (beta coefficient $=0.284$ ) $(2)$ superstructure construction method (beta coefficient $=0.262$ ) (3) construction duration (beta coefficient $=-0.247$ ). This can be interpreted that the longer the construction duration, the lower the loss ratio, and the loss ratio increases according to the increases in the nominal scale of the superstructure type and the superstructure construction method.

Table 5. Summary of the regression model.

\begin{tabular}{ccccc}
\hline Variables & Coef. & Beta Coef. & $\mathbf{p}>|\mathbf{z}|$ & VIF \\
\hline \multicolumn{5}{c}{ Engineering factor } \\
\hline Superstructure & 0.683 & 0.284 & 0.024 & 1.033 \\
\hline Construction method & 0.272 & 0.262 & 0.031 & 1.050 \\
\hline \multicolumn{5}{c}{ Project factor } \\
\hline \multicolumn{5}{c}{ Number of Observations $=367$} \\
F value $=8.924$ \\
Adj- $R^{2}=0.315$
\end{tabular}

\section{Discussion and Conclusions}

The risks in construction projects refer to uncertain conditions and events, and, if they occur, there are negative results in terms of construction costs, time, quality, and so on. Therefore, potential risk factors may be the important aspects that can determine the success or failure of the entire project. Therefore, effective and sustainable risk management can reduce and minimize losses from various potential risk factors. For this reason, understanding and managing possible risk factors should be an essential consideration in construction projects.

It is expected that the recent increase of bridge construction projects and the risk factors resulting from the introduction of the new construction technologies will continue to be on rise. Risk factors in bridge construction projects due to the use of large construction equipment under complex and unstable environmental conditions, and simultaneous ground and high-altitude work have yet to be systematically identified and managed. However, there are limitations in preventing construction disasters only with safety facility equipment, safety guidelines and training, as done so far. Therefore, it has been strongly called for to predict and prepare for possible losses in bridge construction accidents in more reliable and sustainable ways. In this study, the risk factors in bridge construction were analyzed based on the actual data on insurance claim payout from a Korean insurance company, which included 367 material damage claims. The risk prediction model was also developed to predict the future bridge construction losses. Various studies in the past have suggested the analysis of risk factors in general construction as well as bridge construction and pointed out the need for the quantitative data and methodologies in risk analysis. However, due to the lack of detailed loss records, the tendency of companies that hesitate to disclose the actual loss records, the qualitative analyses based on expert surveys and interviews were performed in most previous studies. These previous studies include possible limitations of subjective and intuitive judgment that rely on personal opinions and experiences.

Compared to such qualitative data, on the contrary, it can be said that insurance claim payout data used in this study is by far the most specific and accurate. Further, these quantitative data can be used as objective data for assessing the risks of potential projects and predicting them, using the characteristics particular to each project. In this study, the extent of potential risks through actual losses was able to be identified and the impact on losses was determined through statistical verification with actual case data. As a result, this study found that the three statistically significant risk factors that can 
be used for bridge risk analysis, which are superstructure types, superstructure construction methods and the construction duration.

The findings of this study also demonstrate consistency with the previous studies. That is, the superstructure types indicate that the order of the nominal scale criteria of arch, PSCI and suspension bridges are significant and that it is similar to the classification by the PQ review criteria grade. Additionally, this study found that the level of the risk in the superstructure construction methods tended to be similar to the order of the approximate cost of the construction methods. More specifically, the order of the levels of risk identified in this study was I.L.M, F.C.M, F.S.M and M.S.S, from bottom to top, and the order of the approximate cost of construction identified in a previous study [36] was I.L.M, F.S.M, F.C.M, and M.S.S. In addition, the loss ratio of damages tended to be relatively lower, as the construction duration was extended. This was also similar to the previous studies on general construction and plant construction projects $[37,38]$. However, it is important to note that, although the derived indicators in this study have a correlation with the amount of the insurance payout, or the losses, it does not account for the causality and, thus, further studies to develop the detailed risk prevention measures are required.

As for the implications of this study, the central and local governments and government-invested institutions, which are the main stakeholders of the bridge construction, should develop new technologies in order to improve construction productivity, but also to make an overall improvement of risk management techniques, and to make predictions about future losses based on basic bridge construction planning information, thus enabling preparation for the financial risks. The utilization of the findings of this study is expected to contribute to the establishment of effective measures of risk management reflecting the characteristics of bridge construction and the prevention as well as to minimize losses. In addition, as mentioned earlier, the collected data in this study are quantified and enumerated in numerical values, and thus more objective and reliable. Yet, in terms of the amount of detailed and specific information, the data provided no more than basic and minimal information about the bridge construction projects or damages occurred in the projects. For this reason, for construction companies and insurance companies, the framework of deriving risk factors and developing the risk prediction model presented in this study can also contribute to estimating the financial losses with the available minimum information.

Insurers and reinsurers, particularly, can use the risk factors from this study to reconstruct their loss/risk prediction model. Insurers can reconstruct their own model of measuring potential risks for a particular bridge construction by estimating the possible loss, and use the results as key data for calculating the rates of premiums. Construction companies can assess the maximum possible losses in bridge construction and advance bridge construction planning that minimizes the material losses by optimizing bridge superstructure type, construction method, and construction duration, which were found to be the three significant risk factors in this study. Ultimately, the framework of developing the loss prediction model suggested in this study and the risk factors derived from the framework can be used to efficiently distribute and allocate various resources.

We believe that the value of this study is not a low number to describe the natural phenomena statistically. However, the adjusted $R^{2}$ value is 0.315 , and the remaining variability of the damage is described by an indeterminate predictor. Therefore, future research is needed to determine other potential predictors and add them to the model. Regarding what constitutes as relevant $R^{2}$ value, we have referred to varying opinions of scholars as following:

(1) Falk and Miller [55] suggested that $R^{2}$ values should be equal to or greater than 0.10 in order for the variance explained of a particular endogenous construct to be deemed adequate.

(2) Cohen [56] recommended $\mathrm{R}^{2}$ values for endogenous latent variables are assessed as follows: 0.26 (substantial), 0.13 (moderate), 0.02 (weak).

(3) Chin [57] suggested $R^{2}$ values for endogenous latent variables based on 0.67 (substantial), 0.33 (moderate), 0.19 (weak). 
In order to identify more diverse risk factors and for advancing the accuracy of quantitative risk prediction models in the future, government agencies and construction participators responsible for design and engineering will need to make continuous efforts to establish a broader and more sophisticated loss-recording database system and to establish the technical and institutional foundation to accumulate data in the event of damages and losses.

Author Contributions: Conceptualization, S.A.; Data curation, S.A., J.-M.K.; Funding acquisition, T.K.; Investigation, S.A., J.-M.K.; Methodology, S.A.; Project administration, T.K.; Software, J.-M.K.; Writing—original draft, J.-M.K.; Writing-review and editing, S.A. All authors have read and agree to the published version of the manuscript.

Funding: This research was supported by a grant (NRF-2019R1A2C1009398) from the National Research Foundation of Korea by Ministry of Science, ICT and Future Planning.

Conflicts of Interest: The authors declare no conflict of interest.

\section{References}

1. Kim, J.M.; Kim, T.; Son, K.; Bae, J.; Son, S. A quantitative risk assessment development using risk indicators for predicting economic damages in construction sites of South Korea. J. Asian Archit. Build. Eng. 2019, 18, 472-478. [CrossRef]

2. Wood, G.; Ellis, R.C.T. Risk management practices of leading UK cost consultants. Eng. Constr. Archit. Manag. 2003, 10, 254-262. [CrossRef]

3. Dikmen, I.; Birgonul, M.T.; Arikan, A.E. A critical review of risk management support tools. In Proceedings of the 20th Annual Conference of Association of Researchers in Construction Management, Association of Researchers in Construction Management, Edinburgh, UK, 1-3 September 2004; Heriot-Watt University: Edinburgh, UK, 2004; pp. 1145-1154.

4. Taroun, A.; Yang, J. Dempster-Shafer theory of evidence: Potential usage for decision making and risk analysis in construction project management. Built Hum. Environ. Rev. 2011, 4, 155-166.

5. Cooper, D.F.; Grey, S.; Raymond, G.; Walker, P. Project Risk Management Guidelines: Managing Risk in Large Projects and Complex Procurements; Wiley: Chichester, UK, 2005.

6. California Department of Transportation (Caltrans). Project Risk Management Handbook; Office of Project Management Process Improvement: Sacramento, CA, USA, 2007.

7. Ebrahimnejad, S.; Mousavi, S.M.; Mojtahedi, S.M.H. A fuzzy decision-making model for risk ranking with application to the onshore gas refinery. Int. J. Bus. Contin. Risk Manag. 2009, 1, 38-66. [CrossRef]

8. Tavakkoli-Moghaddam, R.; Mojtahedi, S.M.H.; Mousavi, S.M.; Aminian, A. A jackknife technique to estimate the standard deviation in a project risk severity data analysis. In Proceedings of the 39th International Conference on Computers and Industrial Engineering, Troyes, France, 6-8 July 2009.

9. Morgan, M.G.; Henrion, M. Uncertainty; Cambridge University Press: New York, NY, USA, 1990.

10. United Nations Department of Humanitarian Affairs (UNDHA). Internationally Agreed Glossary of Basic Terms Related to Disaster Management; UNDHA: Geneva, Switzerland, 1992.

11. Stenchion, P. Development and Disaster Management. Aust. J. Emerg. Manag. 1997, 12, 40-44.

12. Crichton, D. The risk triangle. In Natural Disaster Management; Ingleton, J., Ed.; Tudor Rose: London, UK, 1999; pp. 102-103.

13. Jones, R.N.; Boer, R. Assessing current climate risks. In Adaptation Policy Frameworks for Climate Change: Developing Strategies, Policies and Measures; Cambridge University Press: Cambridge, UK, 2004; pp. 91-117.

14. Zou, P.X.; Zhang, G.; Wang, J. Understanding the key risks in construction projects in China. Int. J. Proj. Manag. 2007, 25, 601-614. [CrossRef]

15. Baloi, D.; Price, A.D. Modelling global risk factors affecting construction cost performance. Int. J. Proj. Manag. 2003, 21, 261-269. [CrossRef]

16. Laryea, S. Risk pricing practices in finance, insurance and construction. In Proceedings of the Construction and Building Research Conference of the Royal Institution of Chartered Surveyors, Dublin, Ireland, 4-5 September 2008; University of Reading: London, UK, 2008; pp. 1-16.

17. Baker, S.; Ponniah, D.; Smith, S. Techniques for the analysis of risks in major projects. J. Oper. Res. Soc. 1998, 49, 567-572. [CrossRef] 
18. Khan, F.; Rathnayaka, S.; Ahmed, S. Methods and models in process safety and risk management: Past, present and future. Process Saf. Environ. 2015, 98, 116-147. [CrossRef]

19. Warszawski, A.; Sacks, R. Practical multifactor approach to evaluating risk of investment in engineering projects. J. Constr. Eng. Manag. 2004, 130, 357-367. [CrossRef]

20. Ben-David, I.; Raz, T. An integrated approach for risk response development in project planning. J. Oper. Res. Soc. 2001, 52, 14-25. [CrossRef]

21. Fan, C.F.; Yu, Y.C. BBN-based software project risk management. J. Stat. Softw. 2004, 73, 193-203. [CrossRef]

22. Molenaar, K.R. Programmatic cost risk analysis for highway megaprojects. J. Constr. Eng. Manag. 2005, 131, 343-353. [CrossRef]

23. Cagno, E.; Caron, F.; Mancini, M. A multi-dimensional analysis of major risks in complex projects. Risk Manag. 2007, 9, 1-18. [CrossRef]

24. Keshk, A.M.; Maarouf, I.; Annany, Y. Special studies in management of construction project risks, risk concept, plan building, risk quantitative and qualitative analysis, risk response strategies. Alex. Eng. J. 2018, 57, 3179-3187. [CrossRef]

25. Aziz, N.A.A.; Manab, N.A.; Othman, S.N. Sustainability Risk Management (SRM): An extension of Enterprise Risk Management (ERM) concept. Int. J. Manag. Sustain. 2016, 5, 1-10. [CrossRef]

26. Majdalani, Z.; Ajam, M.; Mezher, T. Sustainability in the construction industry: A Lebanese case study. Constr. Innov. 2006, 6, 33-46. [CrossRef]

27. Bal, M.; Bryde, D.; Fearon, D.; Ochieng, E. Stakeholder Engagement: Achieving Sustainability in the Construction Sector. Sustainability 2013, 5, 695-710. [CrossRef]

28. Shen, L.; Wu, Y.; Zhang, X. Key assessment indicators for the sustainability of infrastructure projects. J. Constr. Eng. Manag. 2011, 137, 441-451. [CrossRef]

29. Adetola, A.; Goulding, J.S.; Liyanage, C.L. Collaborative engagement approaches for delivering sustainable infrastructure projects in the AEC sector: A review. Int. J. Constr. Supply Chain Manag. 2011, 1, 1-24. [CrossRef]

30. Zhang, X.Q.; Kumaraswamy, M.M. Procurement protocols for public-private partnered projects. J. Constr. Eng. Manag. 2011, 127, 351-358. [CrossRef]

31. Wilderer, P.A.; Renn, O.; Grambow, M.; Molls, M.; Mainzer, K. (Eds.) Sustainable Risk Management; Springer International Publishing: Cham, Switzerland, 2018; p. 274.

32. Wang, Y.M.; Elhag, T.M.S. A fuzzy group decision making approach for bridge risk assessment. Comput. Ind. Eng. 2007, 53, 137-148. [CrossRef]

33. Decò, A.; Frangopol, D.M. Risk assessment of highway bridges under multiple hazards. J. Risk Res. 2011, 14, 1057-1089. [CrossRef]

34. Hashemi, H.; Mousavi, S.M.; Mojtahedi, S.M. Bootstrap technique for risk analysis with interval numbers in bridge construction projects. J. Constr. Eng. Manag. 2011, 137, 600-608. [CrossRef]

35. Li, Q.F.; Li, Z.X.; Niu, J. Application of factor analysis to risk evaluation of bridge construction. Adv. Mater. Res. 2011, 243, 1848-1853. [CrossRef]

36. Choudhry, R.M.; Aslam, M.A.; Hinze, J.W.; Arain, F.M. Cost and schedule risk analysis of bridge construction in Pakistan: Establishing risk guidelines. J. Constr. Eng. Manag. 2014, 140, 04014020-1-9. [CrossRef]

37. Yun, S.Y.; Kim, C.H.; Kang, L.S. Development of model for selecting superstructure type of small size bridge using dual classification method. J. Korean Soc. Civ. Eng. 2015, 35, 1413-1420. [CrossRef]

38. Malekly, H.; Mousavi, S.M.; Hashemi, H. A fuzzy integrated methodology for evaluating conceptual bridge design. Expert Syst. Appl. 2010, 37, 4910-4920. [CrossRef]

39. Public Procurement Agency. Available online: http://www.law.go.kr/행정규칙/조달청 입 찰참가자격사전심 사기준/(9746,20191209) (accessed on 3 March 2020).

40. Koh, H.M.; Kim, H.J.; Lim, J.H.; Kang, S.C.; Choo, J.F. Lifetime design of cable-supported super-long-span bridges. In Proceedings of the 5th International Conference on Bridge Maintenance, Safety and Management, Philadelphia, PA, USA, 11-15 July 2010; CRC Press: London, UK, 2010; pp. 26-42.

41. Jo, B.W.; Park, J.C.; Kim, C.H. Wind characteristics of existing long span bridge based on measured data. J. Civ. Eng. 2005, 9, 219-224. [CrossRef]

42. Yang, Y.; Gang, Y.; Wei, F.; Qin, W. Buffeting performance of long-span suspension bridge based on measured wind data in a mountainous region. J. Vibroeng. 2018, 20, 621-635. [CrossRef] 
43. Elsaid, A.; Seracino, R. Rapid assessment of foundation scour using the dynamic features of bridge superstructure. Constr. Build. Mater. 2014, 50, 42-49. [CrossRef]

44. Giroux, R.P. Relevance of Roebling. J. Perform. Constr. Facil. 2009, 23, 2-4. [CrossRef]

45. Won, J.H.; Kim, G.Y. Structural Safety Analysis of a Long Span Cable-stayed Bridge with a Partially Earth Anchored Cable System on Dynamic Loads during Construction. J. Korean Soc. Saf. 2016, 31, 104-110. [CrossRef]

46. Sampaio, A.Z.; Martins, O.P. The application of virtual reality technology in the construction of bridge: The cantilever and incremental launching methods. Autom. Constr. 2014, 37, 58-67. [CrossRef]

47. Kwak, H.G.; Son, J.K. Determination of design moments in bridges constructed with a movable scaffolding system (MSS). Comput. Struct. 2006, 84, 2141-2150. [CrossRef]

48. Pan, N.F. Fuzzy AHP approach for selecting the suitable bridge construction method. Autom. Constr. 2008, 17, 958-965. [CrossRef]

49. Kim, S.B.; Cho, J.H. Development of the approximate cost estimating model for PSC box girder bridge based on the breakdown of standard work. J. Korean Soc. Civ. Eng. 2013, 33, 791-800. [CrossRef]

50. Kim, J.M.; Kim, T.; Bae, J.; Son, K.; Ahn, S. Analysis of plant construction accidents and loss estimation using insurance loss records. J. Asian Archit. Build. Eng. 2019, 18, 507-516. [CrossRef]

51. Ryu, H.; Son, K.; Kim, J.M. Loss prediction model for building construction projects using insurance claim payout. J. Asian Archit. Build. Eng. 2016, 15, 441-446. [CrossRef]

52. Vaughan, E.; Vaughan, T. Essential of Insurance: A Risk Management Perspective; John Wiley \& Sons: New York, NY, USA, 1995; p. 656.

53. Kim, J.M.; Kim, T.; Son, K.; Yum, S.G.; Ahn, S. Measuring Vulnerability of Typhoon in Residential Facilities: Focusing on Typhoon Maemi in South Korea. Sustainability 2019, 11, 2768. [CrossRef]

54. Kim, J.M.; Woods, P.K.; Park, Y.J.; Kim, T.; Son, K. Predicting hurricane wind damage by claim payout based on Hurricane Ike in Texas. Geomat. Nat. Hazards Risk. 2016, 7, 1513-1525. [CrossRef]

55. Falk, R.F.; Miller, N.B. A Primer for Soft Modeling; University of Akron Press: Akron, OH, USA, 1992.

56. Cohen, J. Statistical Power Analysis for the Behavioral Sciences, 2nd ed.; Lawrence Erlbaum Associates, Inc.: Mahwah, NJ, USA, 1988.

57. Chin, W.W. The Partial Least Squares Approach to Structural Equation Modeling. In Modern Methods for Business Research; Marcoulides, G.A., Ed.; Lawrence Erlbaum Associates: Mahwah, NJ, USA, 1998; pp. 295-358.

(C) 2020 by the authors. Licensee MDPI, Basel, Switzerland. This article is an open access article distributed under the terms and conditions of the Creative Commons Attribution (CC BY) license (http://creativecommons.org/licenses/by/4.0/). 